Original Research Article

\title{
Antibiotics-related adverse drug reactions at a tertiary care hospital in North India
}

\author{
Seema Rani ${ }^{1}$, Bhawna Sharma ${ }^{1}$, Tarun $^{2}{ }^{*}$, Sanjeev Kumar ${ }^{3}$, Rahul Saini $^{1}$
}

${ }^{1}$ Department of Pharmacology,
${ }^{2}$ Department of Medicine,
${ }^{3}$ Department of Orthopaedics,
BPS Government Medical
College for Women, Khanpur
Kalan, Sonepat, Haryana, India

Received: 30 July 2019

Revised: 10 September 2019

Accepted: 11 September 2019

*Correspondence to:

Dr. Tarun,

Email:drtarun7@gmail.com

Copyright: (C) the author(s), publisher and licensee Medip Academy. This is an openaccess article distributed under the terms of the Creative Commons Attribution NonCommercial License, which permits unrestricted noncommercial use, distribution, and reproduction in any medium, provided the original work is properly cited.

\begin{abstract}
Background: Antibiotics are considered to be commonly used drugs in hospital setting due to higher prevalence of infectious diseases especially in India. So, the present study was conducted to assess the incidence of adverse drug reactions (ADRs) due to antibiotics and analyze for causality of adverse drug events reported.
\end{abstract}

Methods: The present retrospective and observational, study was conducted in BPS GMC for women, Khanpur Kalan, Sonepat, Haryana which is a 500 bedded government medical hospital situated in rural area between March 2016 to February 2019 (i.e., 3 years). Patients of either sex or age who developed ADRs by any route were included in the study.

Results: $300(38.65 \%)$ cases were reported due to antibiotics out of total 776 ADR cases. $3 \%$ cases were serious. Adults $(65 \%)$ were found to be most commonly affected by ADRs. Among antibiotics, cephalosporins and penicillins $(15.98 \%)$ were the major culprit to cause adverse events followed by nitroimidazoles $(15.2 \%)$ and antitubercular drugs and fluoro quinolones $(13.16 \%)$. The most affected organ system was skin $(49.33 \%)$ followed by the gastrointestinal system $(33 \%)$. As per WHO scale of causality assessment, $33.33 \%$ and $67.67 \%$ reported cases were found to probably and possibly related to adverse events respectively.

Conclusions: Antibiotics are most commonly prescribed drugs so its monitoring regarding ADRs may benefit the clinicians in early identification and management of ADRs so that quality of life of patient can be safeguarded at an earliest.

Keywords: Pharmacovigilance, ADR, Pharmacovigilance Program of India, Antibiotics

\section{INTRODUCTION}

World Health Organisation (WHO) defines adverse drug reaction (ADR) as "any response to a drug which is noxious and unintended, and which occurs at doses normally used in man for prophylaxis, diagnosis or therapy of disease or for the modification of physiologic function." Adverse drug reaction is the 7th most common cause of death with $6.5 \%$ of admissions in National Health Service (NHS) hospitals is due to ADRs. ${ }^{1}$ Sometimes, ADR-related costs may exceed the cost of the treatment of disease. ${ }^{2}$
Antibiotics are considered to be the commonly used drugs in hospital setting due to higher prevalence of infectious diseases especially in India. These are observed to be the main culprit of ADRs. ${ }^{3,4} 3.2-40.9 \%$ of ADRs are reported due to antibiotics as per various studies conducted in Indian population. ${ }^{5-8}$ This may be because of self-medication, over-the-counter use, and irrational prescription. Also excessive and irrational use of antibiotics may cause antibiotic resistance. ${ }^{9}$ Thus, the rational use of antibiotics is a major health need. 
Phatak et al rightly said that "drugs are double edged weapons", so ADR monitoring is one of the crucial part during the treatment period of patient. ${ }^{10}$

Uppsala monitoring centre, Sweden in collaboration with WHO was first established in the year 1971with its important role in maintaining the international database of ADRs.

In order to prevent and monitor ADRs, pharmacovigilance centers are being established in tertiary care centres in India. Establishing an antibiotic policy in every institution and ensuring that the best choice among antibiotics should be prescribed by physicians can also prevent ADRs.

Thus, the present study was conducted to assess the incidence of ADRs due to antibiotics and analyze for causality of adverse drug events reported to ADR Monitoring Centre, Department of Pharmacology, BPS GMC for women, Khanpur Kalan, Sonipat, Haryana, India.

\section{METHODS}

The present retrospective, observational study was conducted in northern tertiary care hospital situated in rural area. The Department of Pharmacology, BPS GMC for women, Khanpur Kalan, Sonepat, Haryana, India which is one of the ADR monitoring centre (AMC) under the Pharmacovigilance Program of India (PvPI) since January 2014. Suspected adverse events due to antibiotics were analyzed from the data collected from OPD and IPD of all clinical departments of hospital on regular basis for a period of 3 years from March 2016 to February 2019. All patients of either sex and of any age who developed ADRs due to antibiotics by any route during the above mentioned time period were included in the study. The causality assessment of the reported ADRs was carried using WHO-UMC scale for causality assessment scale. In the WHO-UMC scale, the causality terms used are certain, probable, possible, unlikely, conditional and unassessable.

\section{RESULTS}

A total of 776 ADR cases were reported during the study period of 3 years. Out of total 776 cases, 300 (38.65\%) cases were reported due to antibiotics. Out of 300 cases reported, $272(90.66 \%)$ cases were reported in IPD and $28(9.34 \%)$ cases were reported in OPD setup. Our study revealed that female patients $(52.34 \%)$ predominated over male patients $(47.66 \%)$ in ADR occurrence. Age distribution showed maximum ADR occurrence in adults $195(65 \%)$ followed by children 59 (19.67\%) and geriatrics $46(15.33 \%)$ (Figure 1). Maximum number of ADRs were reported from surgery department (80) followed by medicine (46), paediatrics (38) and respiratory medicine (33) (Figure 2).

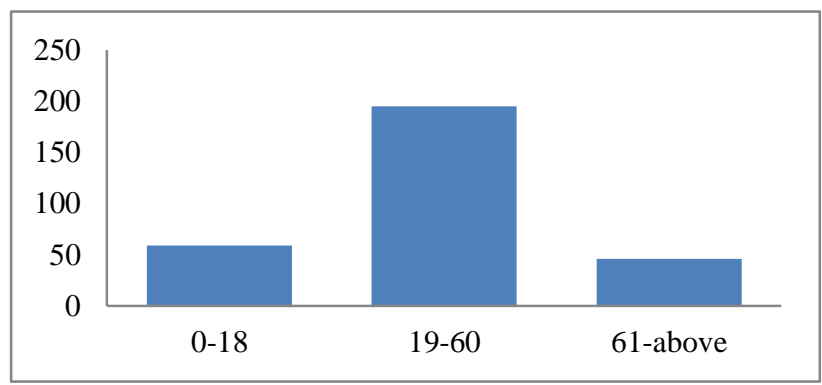

Figure 1: Age group distribution of ADRs.

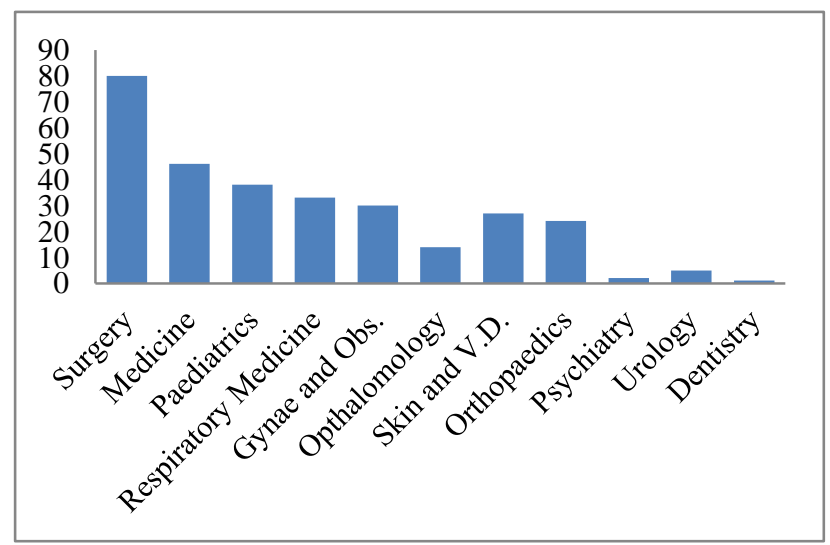

Figure 2: Department wise distribution of ADRs.

Table 1: Therapeutic class of antibiotics implicated to cause ADR.

\begin{tabular}{|llll|}
\hline S. no. & Class of drug & No. of cases reported & $\%$ of ADR \\
\hline $\mathbf{1}$ & Penicillins (augmentin, amoxicillin, tazobactam, Piptaz & 51 & 17 \\
\hline $\mathbf{2}$ & Cephalosporins (ceftriaxone, cephalexin, cefixime, cefotaxime) & 51 & 17 \\
\hline $\mathbf{3}$ & Quinolones (ciprofloxacin, levofloxacin, ofloxacin, Moxicip KT & 42 & 14 \\
\hline $\mathbf{4}$ & Nitroimidazoles (metronidazole, tinidazole) & 39 & 13 \\
\hline $\mathbf{5}$ & Aminoglycosides (amikacin, gentamicin, streptomycin) & 17 & 5.67 \\
\hline $\mathbf{6}$ & Macrolides (azithromycin) & 2 & 0.67 \\
\hline $\mathbf{7}$ & Glycopeptide (vancomycin) & 13 & 8.33 \\
\hline $\mathbf{8}$ & Oxazolidinone (linezolid) & 4 & 1.33 \\
\hline $\mathbf{9}$ & Sulfonamides (septra, sulfasalazine) & 4 & 1.33 \\
\hline $\mathbf{1 0}$ & Carbapenems (meropenem) & 4 & 1.33 \\
\hline $\mathbf{1 1}$ & Antitubercular drugs & 42 & 14 \\
\hline
\end{tabular}

Continued. 


\begin{tabular}{|c|c|c|c|}
\hline S. no. & Class of drug & No. of cases reported & $\%$ of ADR \\
\hline 12 & $\begin{array}{l}\text { Combined antibiotics (Ciplox TZ), doxorubucin, } \\
\text { nitrofurantoin, norfloxacin/tinidazole, norfloxacin or } \\
\text { tinidazole, nefzone }\end{array}$ & 30 & 10 \\
\hline 13 & Tetracycline (doxycycline) & 1 & 0.33 \\
\hline
\end{tabular}

Among the antimicrobial agents, cephalosporins (ceftriaxone, cephalexin, cefixime, cefotaxime)- 51 $(15.98 \%)$ and penicillins (augmentin, amoxicillin, tazobactam, Piptaz)- 51 (15.98\%) were found to be the major culprit to cause adverse events. Nitroimidazoles (metronidazole, tinidazole)- 48 (15.12\%), antitubercular drugs-42 (13.16\%) and quinolones (ciprofloxacin, levofloxacin, ofloxacin, Moxicip KT)- 42 (13.16\%) were $2^{\text {nd }}$ and $3^{\text {rd }}$ the most common culprits. Other antibiotics like aminoglycosides (amikacin, gentamicin, and streptomycin), glycopeptide (vancomycin), sulfonamides (septra, sulfasalazine), oxazolidinone (linezolid), carbapenems (meropenem), macrolides (azithromycin) and tetracycline (doxycycline), doxorubucin, nitrofurantoin were also reported to cause adverse events (Table 1).

Almost all the ADRs (94\%) were observed in patients receiving combination drug therapy (i.e., >2 medicines) when compared to patients receiving single drug therapy. $38(11.19 \%)$ cases were reported due to fixed drug combinations like ciprofloxacin or tinidazole, norfloxacin or tinidazole, norfloxacin or tinidazole, ceftriaxone or sulbactam.

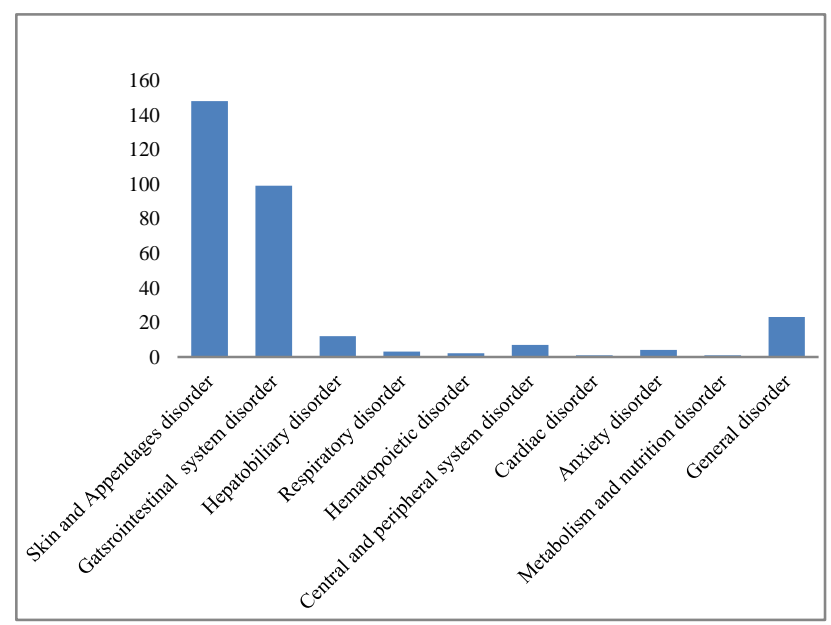

Figure 3: Organ system affected due to ADRs.

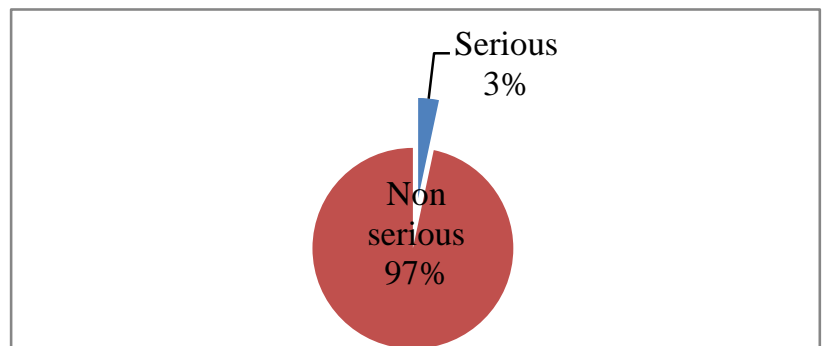

Figure 4: Seriousness of ADRs due to antibiotics.

The most affected organ system was skin (49.33\%) followed by the gastrointestinal system (33\%) (Figure 3). $10(3.33 \%)$ cases were serious and $290(96.67 \%)$ were non-16 serious (Figure 4).

Most of the ADR were found to be 'type A' reaction. Frequently observed types of ADRs were rashes $(20.67 \%)$, vomiting $(14.67 \%)$, itching $(13.67 \%)$, diarrhea $(11.00 \%)$, fever $(4.67 \%)$, raised liver enzymes $(3.67 \%)$, swelling of skin, fixed drug eruption and erythema $(2.67 \%)$, etc. The other ADRs that were observed included decreased appetite, cough, neutropenia, facial puffiness, headache, shivering, psoriasiform rash, halitosis, alopecia, darkening of nails, dizziness, palpitation, lichenoid drug eruption, urticaria, peeling of skin, metallic taste, excoriated skin lesions, restlessness, etc.

Rare and serious adverse events (SUSAR) reported was vancomycin induced seizure and ceftriaxone and paracetamol induced urticarial vasculitis. The serious ADRs reported were antitubercular drugs induced elevated liver enzymes, hyperbilirubinaemia and excoriated skin lesions, hepatitis, psoriasiform rash; ciprofloxacin and metronidazole induced Stevens Johnson syndrome; ciprofloxacin or tinidazole induced neutropenia and meropenem and hydrocortisone induced hypokalemia, gentamicin induced raised serum urea and creatinine levels, ciprofloxacin induced facial edema, breathlessness and tachycardia (Table 2).

Table 2: Serious ADRs and implicated drugs with dose and route of administration.

\begin{tabular}{|c|c|c|c|}
\hline & Drug reaction & $\begin{array}{l}\text { Drugs implicated with dose } \\
\text { and route of administration }\end{array}$ & Condition indicated for \\
\hline \multirow[t]{2}{*}{1.} & \multirow[t]{2}{*}{ Steven Johnson Syndrome } & Inj. ciprofloxacin & \multirow[t]{2}{*}{ Acute gastroenteritis } \\
\hline & & Inj. metronidazole & \\
\hline 2. & Raised serum urea and creatinine levels & Inj. gentamicin & Postoperative antibiotic \\
\hline \multirow[t]{3}{*}{3.} & \multirow[t]{3}{*}{ Hypokalemia } & Inj. Meropenem & Post-operative antibiotic \\
\hline & & Inj. hydrocortisone & \multirow{2}{*}{$\begin{array}{l}\text { Swelling in intra- } \\
\text { abdominal region }\end{array}$} \\
\hline & & Inj. meropenem & \\
\hline
\end{tabular}




\begin{tabular}{|c|c|c|c|}
\hline $\begin{array}{l}\text { S. } \\
\text { no. }\end{array}$ & Drug reaction & $\begin{array}{l}\text { Drugs implicated with dose } \\
\text { and route of administration }\end{array}$ & Condition indicated for \\
\hline 4. & Neutropenia & Tab. ciprofloxacin or tinidazole & Acute gastroenteritis \\
\hline 5. & Facial edema with breathlessness, tachycardia & Inj. ciprofloxacin & Acute gastroenteritis \\
\hline 6. & $\begin{array}{l}\text { Elevated liver enzymes, elevated bilirubin levels } \\
\text { excoriated skin lesions, hepatitis, psoriasis form } \\
\text { rash }\end{array}$ & $\begin{array}{l}\text { Antitubercular drugs (isoniazid, } \\
\text { rifampicin, pyrazinamide and } \\
\text { ethambutol tablets) }\end{array}$ & Respiratory tuberculosis \\
\hline \multicolumn{4}{|c|}{ Unexpected and serious ADR and implicated drugs with dose and route of administration } \\
\hline 1. & Seizure Inj. vancon & Inj. vancomycin (200 mg IV) & Pleural fluid effusion \\
\hline \multirow[t]{2}{*}{2.} & \multirow[t]{2}{*}{ Urticarial vasculitis } & e $(1 \mathrm{~g} \mathrm{IV})$ & \multirow{2}{*}{$\begin{array}{l}\text { Upper respiratory tract } \\
\text { infection }\end{array}$} \\
\hline & & nol (500 mg oral) & \\
\hline
\end{tabular}

Number of cases reported in causality assessment was done as per WHO-UMC scale of causality assessment. $33.33 \%$ reported cases were found to probably related to adverse events and $66.67 \%$ cases were found to be possibly related to adverse events using WHO-UMC scale (Figure 5).

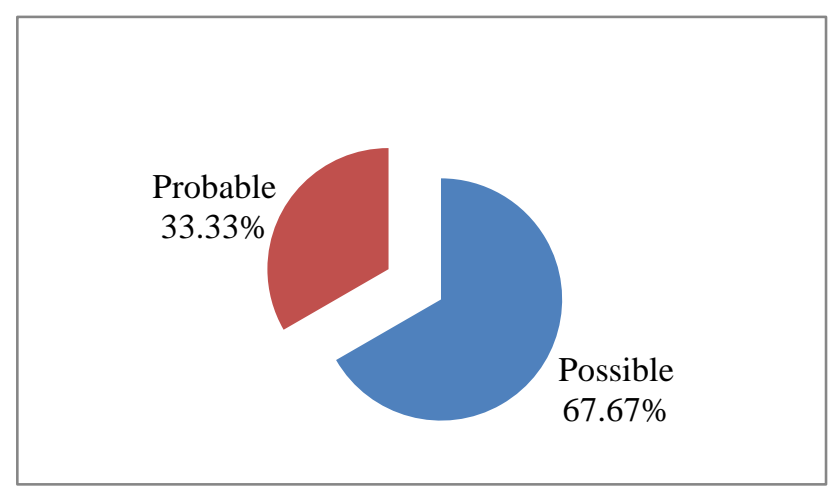

\section{Figure 5: Causality assessment using WHO-UMC} scale.

\section{DISCUSSION}

ADRs are considered to be one of the reasons for increase in healthcare cost nowadays. They are even one of the major causes of death among patients. Antibiotics are responsible for $11 \%$ of iatrogenic disease as per Darchy's report. ${ }^{11}$ So this retrospective study was conducted to highlight the status of adverse drug reactions due to antibiotics in a tertiary care hospital so that healthcare professionals get sensitize about commonly observed ADRs due to antibiotics which will help to minimize risks among patients.

The incidence rate of antibiotic adverse reactions in this study was found to be $38.65 \%$, which is comparable to other study by Geer et al $2016 .^{8}$ ADR occurrences due to antibiotics is more in female than in male as per our study. Age analysis showed the predominance of adult patients followed by children and geriatrics that may be due to age related pharmacokinetic and pharmacodynamic changes and the presence of comorbid illnesses and multiple drugs along with infectious diseases. The study conducted by Starveva et al and Hussain et al also showed adult age group and female predominance which is in contrast to study conducted by Jose et al that showed male predominance. ${ }^{12-15}$

Maximum number of adverse drug reactions was reported from surgery department which was followed by general medicine and pediatrics departments. The reason for this result can be usage of antibiotics at high frequency for treatment and prophylaxis of various diseases in these departments. Skin and GIT were documented to be the common organ system affected by adverse drug reactions due to antibiotic. This study also revealed the same which is in resemblance to various studies conducted earlier. ${ }^{13,14,16}$ Other studies also showed the predominance of cutaneous manifestations to be the main cause for ADRs. ${ }^{11,16,19}$ In one study, predominance of the gastrointestinal system followed by the skin in ADR occurrence was also reported. ${ }^{17,18}$ Rash and itching were found to be most commonly reported adverse drug reactions affecting dermatological system. Many previous studies showed predominance of such adverse drug reactions. $^{13,16,19}$

The penicillins and cephalosporins were reported to be the major culprits of adverse drug reactions among antibiotic class in inpatient settings, followed by fluoroquinolones and nitroimidazoles. A study conducted by Stavreva et al also revealed the predominance of betalactams. ${ }^{11}$ Cephalosporins and fluoroquinolones were the major group contributing to adverse drug reactions as per one of the study. ${ }^{13}$ Vancomycin and penicillins were most frequent antibiotics causing adverse drug reactions in the study of Priyadharsini et al. ${ }^{12,13,20}$

Type A ADR was found to be predominated in our study according to Rawlin and Thompson classification of ADR which is same as the study conducted by Richa et al. ${ }^{12,16}$ While in another study by Suthar and Desai, all the reported reactions were Type $\mathrm{B}$ reactions. ${ }^{21}$

The causality assessment of ADRs was done using the WHO UMC causality assessment scale in which no reactions were found to be unlikely and majority were probable with a less number of possible reactions. These data correlate with the study of Richa et al and opposite to the study by Modi et al because they reported more number of possible reactions. ${ }^{22-25}$ 


\section{CONCLUSION}

Antibiotics are most commonly prescribed drugs so its monitoring regarding adverse drug reactions is an important need. In our study, penicillin and cephalosporins were the most common causes of ADRs among antibiotics. The most frequently experienced clinical feature was cutaneous reactions. This study may benefit the clinicians in early identification and management of adverse drug reactions due to antibiotics so that quality of life of patient can be safeguarded at an earliest.

\section{ACKNOWLEDGEMENTS}

Authors would like to acknowledge National Coordination Centre-Pharmacovigilance Programme of India, Indian Pharmacopoeia Commission, Ministry of Health and Family Welfare, Government of India for their kind support to conduct this study.

Funding: No funding sources Conflict of interest: None declared

Ethical approval: The study was approved by the Institutional Ethics Committee

\section{REFERENCES}

1. Hettihewa LM, Sirisena B. Causality assessment and the severity of the adverse drug reactions (ADR) actively detected in hospital-in patients in tertiary care hospital Sri Lanka: prospective observational survey. Asian J Res Biol Pharm Sci. 2014;2(1):1-10.

2. World Health Organization. Pharmacovigilance. Available at: http://www.who.int/medicines/areas/ quality_safety/safety_efficacy/pharmvigi/en/index.ht ml. Accessed 10 January 2015.

3. Patil SB, Raikar SR, Janardhan M, Rao YV, Bhaskar HN, Vahila N. A profile of adverse drug reactions in a rural tertiary care hospital. Nat J Physiol Pharm Pharmacol. 2016; 6(6):559-62.

4. Sriram S, Ghasemi A, Ramasamy R, Devi M, Balasubramanian R, Ravi TK. Prevalence of adverse drug reactions at a private tertiary care hospital in south India. J Res Med Sci. 2011;16(1):16-25.

5. Vijaishri R, Andhuvan G. A prospective study on antibiotics-associated spontaneous adverse drug reaction monitoring and reporting in a tertiary care hospital. Asian J Pharm. 2017;11(4):834-40.

6. Jindal M, Sharma RK. Antimicrobial-related adverse drug reaction in a tertiary care hospital. Asian J Pharm Clin Res. 2017;10(8):229-31.

7. Sharma S, Khajuria V, Mahajan V, Gillani Z, Richa, Tandon V. Adverse drug reactions profile of antimicrobials: A 3-year experience, from a tertiary care teaching hospital of India. Indian $\mathbf{J}$ Med Microbiol. 2015;33(3):393-400.

8. Geer M, Koul P, Tanki S, Shah M. Frequency, types, severity, preventability and costs of adverse drug reactions at a tertiary care hospital. J Pharmacol Toxicol Method. 2016;81:323-34.

9. Park SH. Is antibiotic resistance microorganism becoming a significant problem in acute cholangitis in Korea. Clin Endosc. 2012;45:111-2.

10. Phatak A, Nagari BG. Safety of medicines. Pharma Times. 2003;35:19-21.

11. Shamna M, Dilip C, Ajmal M, Mohan PL, Shinu C, Jafer CP, et al. A prospective study on Adverse Drug Reactions of antibiotics in a tertiary care hospital. Saudi Pharm J. 2014;22:303-8.

12. Stavreva G, Pendicheva D, Pandurska A, Marev R. Detection of adverse drug reactions to antimicrobial drugs in hospitalized patients. Trakia J Sci. 2008;6(1):7-9.

13. Hussain MM, Girhepunje K, Pal R, Siddiqua SS. Incidence of adverse drug reactions in a tertiary care hospital: a systematic review and meta-analysis of prospective studies. Der Pharmacia Lettre. 2010;2(3):358-68.

14. Jimmy J, Rao Padma GM, Jimmy B. Adverse drug reactions to fluoroquinolone antibiotics-analysis of reports received in a tertiary care hospital. Int J Risk Saf Med. 2008;20:169-80.

15. Suthar JV, Desai SV. A study of adverse cutaneous drug reactions in outdoor patients attending to skin and V.D. Department of Shree Krishna Hospital, Karamsad. Int $\mathbf{J}$ Res Pharm Biomed Sci. 2011;2(1):274-9.

16. Oshikoya KA, Njokanma OF, Chukwara HA, Ojo IO. Adverse drug reactions in Nigerian children. Paediatr. Perinat Drug Ther. 2007;8:81-8.

17. Benjamin H, Louis MJ, Maryse LM. Adverse drug reactions and off-label drug use in paediatric outpatients. Br J Clin Pharmacol. 2002; 54:665-70.

18. Jonville-Bera AP, Giraudeau B, Blanc P, BeauSalinas F, Autret-Leca E. Frequency of adverse drug reactions in children: a prospective study. Br J Clin Pharmacol. 2002;53:207-10.

19. Granowitz, Eric V, Brown, Richard B. Antibiotic adverse reactions and drug interactions. Crit Care Clin. 2008;24:421-42.

20. Priyadharsini R, Adhithan SC, Sreenivasan S, Kumar. A study on adverse drug reactions in paediatric patients. J Pharmacol Pharmacother. 2011;2(4):277-80.

21. Suthar JV, Desai SV. A study of adverse cutaneous drug reactions in outdoor patients attending to skin and V.D. Department of Shree Krishna Hospital, Karamsad. Int $\mathbf{J}$ Res Pharm Biomed Sci. 2011;2(1):274-9.

22. Sharma S, Khajuria V, Mahajan V, Gillani Z, Richa, Tandon V. Adverse drug reactions profile of antimicrobials: A 3-year experience, from a tertiary care teaching hospital of India. Indian $\mathrm{J}$ Med Microbiol. 2015;33(3):393-400.

23. Nagaiah BH, Patil SB, Vahila N, Rao YK, Raikar SR, Sajid M. Analysis of adverse drug reactions of antimicrobial agents reported to ADR monitoring 
centre of a rural tertiary care teaching hospital. Int $\mathbf{J}$ Basic Clin Pharmacol. 2017;6(5):1151-4.

24. Dhar K, Sinha A, Gaur P, Goel R, Chopra VS, Bajaj U. Pattern of adverse drug reactions to antibiotics commonly prescribed in department of medicine and pediatrics in a tertiary care teaching hospital, Ghaziabad. J Appl Pharm Sci. 2015;5(4):78-82.

25. Jung IY, Kim JJ, Lee SJ, Kim J, Seong H, Jeong W, et al. Antibiotic-Related Adverse Drug Reactions at a
Tertiary Care Hospital in South Korea. BioMed Res Int. 2017;2017:1-7.

Cite this article as: Rani S, Sharma B, Tarun, Kumar S, Saini R. Antibiotics-related adverse drug reactions at a tertiary care hospital in North India. Int J Basic Clin Pharmacol 2019;8:2288-93. 